\title{
O TRATADO DE COOPERAÇÃO AMAZÔNICA E A GESTÃO COMPARTILHADA DE RECURSO NATURAIS: A EFETIVAÇÃO DOS SEUS PROJETOS.
}

\section{THE AMAZON COOPERATION TREATY AND SHARED MANAGEMENT OF NATURAL RESOURCES: THE EFFECTIVE OF YOUR PROJECTS.}

\author{
${ }^{1}$ Juan Pablo Ferreira Gomes \\ ${ }^{2}$ Erivaldo Cavalcanti e Silva Filho
}

\section{RESUMO}

O presente artigo tem como principal objetivo analisar o desenvolvimento de mecanismos de cooperação através do Tratado de Cooperação Amazônica e da Organização do Tratado de Cooperação Amazônica - OTCA. Para tanto, realizou-se um histórico sobre a formação e elaboração do tratado, bem como a implementação de projetos e efetivação dos princípios existentes ao longo do tempo. Nossa metodologia foi a pesquisa qualitativa com o intuito de identificar e interpretar as informações do assunto posto, além da utilização de material bibliográfico.

Palavras-chave: Cooperação internacional, Organização do tratado de cooperação amazônica, Desenvolvimento sustentável

\begin{abstract}
This article aims to analyze the development of cooperation mechanisms through the Amazon Cooperation Treaty and the Amazon Cooperation Treaty Organization - ACTO. Therefore, there was a history of the formation and development of the treaty, as well as project implementation and enforcement of existing principles over time. Our methodology was qualitative research in order to identify and interpret the subject of the information office, in addition to the use of bibliographic material.
\end{abstract}

Keywords: International cooperation, Amazon cooperation treaty organizations, Sustainable development

\footnotetext{
${ }^{1}$ Mestrando em Direito Ambiental pela Universidade do Estado do Amazonas - UEA, Amazonas (Brasil). Professor pela Faculdade La Salle de Manaus, UNILASALLE, Rio Grande do Sul (Brasil).

E-mail: juanpablogomes1@gmail.com

${ }^{2}$ Doutor em Desenvolvimento Sustentável pela Universidade Federal do Pará - UFPA, Pará (Brasil). Professor pela Universidade do Estado do Amazonas - UEA, Amazonas (Brasil). E-mail: erivaldofilho@ hotmail.com
} 


\section{Introdução}

Em 03 de julho de 1978, Bolívia, Brasil, Colômbia, Equador, Guiana, Peru, Suriname e Venezuela formalizaram o Tratado de Cooperação Amazônica - TCA, cujo objetivo principal foi realizar esforços e ações conjuntas a fim de promover o desenvolvimento harmônico em seus respectivos territórios amazônicos, com proveitos para todos os estados-partes, associando-se desenvolvimento com a preservação do meio ambiente e a conservação e utilização racional dos recursos naturais.

Assim, o Tratado de Cooperação Amazônica (TCA) surgiu como uma tentativa de se promover a cooperação internacional nas zonas transfronteiriças através de projetos de integração, para se tornar o principal instrumento jurídico no que pertine à gestão dos recursos naturais da Amazônia, buscando uma melhor qualidade de vida de seus habitantes, com efetivação de direitos humanos fundamentais e a conservação e utilização racional dos recursos naturais.

Ao longo de quase quarenta anos muitos projetos se desenvolveram, a própria perspectiva de gestão compartilhada de recursos naturais ganhou um novo contorno e a própria concepção de desenvolvimento passou a ser atrelada à necessária sustentabilidade, o que por si justifica a presente pesquisa.

Assim, torna-se imperioso realizar um breve histórico da formação do Tratado e da Organização do Tratado de Cooperação Amazônica, bem como investigar os principais projetos em desenvolvimento na contemporaneidade. Para tanto, com o intuito de cumprir tais objetivos, utilizamos a metodologia da pesquisa qualitativa que consistiu em identificar e interpretar as informações necessárias sobre o assunto posto e descrever, afim de promover seu objetivo, através de uma pesquisa bibliográfica, o tema, que assim consubstanciou o trabalho. 


\section{Contextualização histórica do Tratado de Cooperação Amazônica}

A Região Amazônica possui diversas idiossincrasias e peculiaridades que levam à divergentes e até antagônicas interpretações quanto às suas dimensões.

Marciano (2002, p. 55) aponta três dimensões fundamentais para compreensão mínima da realidade amazônica:

1. A Amazônia clássica - Corresponde o Norte do Brasil, sendo formada pelos Estados do Acre, Amazonas, Pará, Rondônia, Roraima e Amapá, com uma superfície de 3,5 milhões de $\mathrm{km}^{2}$;

2. A Amazônia Legal - Decorrente da Lei 1.806/1953, quando foi criada a Superintendência da Valorização Econômica da Amazônia (SPVEA), depois denominada Superintendência do Desenvolvimento da Amazônia (SUDAM), a qual inclui além da Amazônia, o Estado do Maranhão na sua parte ocidental, a Leste do meridiano 44 e ao Norte de Goiás e Mato Grosso, acima dos paralelos 13 e 16 de latitude Sul, com uma superfície que ultrapassa 5 milhões de $\mathrm{km}^{2}$;

3. Pan-Amazônia internacional - Decorrente do Pacto de Cooperação Amazônico, assinado em 1978, por oito países sul-americanos: Brasil, Colômbia, Equador, Guiana, Peru, Suriname, Venezuela e Bolívia.

Ainda que pesem divergências, os números destacam a grandeza da região, bem como seu potencial e interesse coletivo dada a presença da maior bacia sedimentar do planeta, o maior ecossistema florestal de toda a biosfera, tudo sob a manta de um mar verde aparentemente intransponível e inexpugnável.

O Tratado de Cooperação Amazônica foi assinado no crepúsculo do regime de militar no Brasil, durante o governo Geisel (1974-1979) que pautou sua política externa sob os ditames da concepção de desenvolvimento e segurança, próprios da bipolaridade que o mundo enfrentava no contexto da Guerra Fria, como salienta Magalhães (2014, p. 05): 
No início do Governo Geisel, confirmou-se a retomada do discurso externo brasileiro que preconizava a noção de autonomia, com os limites impostos pelo mundo bipolar. Lembra Fonseca a primeira mensagem de Geisel ao Congresso em que afirmava: “A política externa brasileira, coerente com as tradições do país e animada pelo espírito que preside as realizações no plano interno, dos governos da Revolução, guia-se pelos magnos objetivos nacionais do desenvolvimento e da segurança".

Segundo Silveira (2005, p. 58):

\begin{abstract}
O binômio segurança/desenvolvimento iniciado na década de 60 e sustentado pelos governos militares para a Amazônia continuava em voga, tendo ainda que lidar com "os óbvios interesses geopolíticos da região", e pela "necessidade urgente e fundamental, ressentida pelos Países signatários, de por fim nalguns problemas fronteiriços, máxime aqueles que diziam respeito à navegação fluvial.
\end{abstract}

Inobstante isso, havia uma evidente divergência ideológica entre os estados envolvidos, “a relação de desconfiança envolvendo o Brasil e a maioria dos seus vizinhos da Bacia Amazônica era uma dificuldade concreta para maior aproximação brasileira com os países do Cone Sul” (PASSOS, 1998, p. 113).

A construção pelo Brasil da rodovia Transamazônica e, posteriormente, da rodovia Perimetral Norte, despertou uma percepção suspeita por parte do governo peruano de Velasco Alvarado (que não se alinhava às posições estadunidenses ao contrário dos brasileiros) e de muitos círculos latino-americanos (PASSOS, 1998, p. 113-115).

O clima hostil somente se dissolveu com a assinatura de acordos bilaterais de cooperação entre Brasil e Peru, em 1976, estando o último país sob a presidência de Morales Bermudez. No que pertine a Colômbia, o Brasil estabeleceu um acordo destinado à prospecção 
de jazidas de carvão colombianas num consórcio envolvendo as empresas Siderbrás, por parte do Brasil, e Ingeominas, da Colômbia. Quanto à Venezuela, após o golpe de 1964, houve o rompimento das relações diplomáticas entre os países até 1977, e só com a visita do então Presidente Carlos Andrés Perez ao Brasil, onde se firmou o Acordo de Amizade e Cooperação, o qual amenizou a imagem imperialista ou hegemônica que Brasília passava antes a transparecer (PASSOS, 1998, p. 114).

Interesses comerciais ainda atraíam o Brasil em face da Bolívia (gás natural), Equador (após a descoberta de petróleo na Amazônia Equatoriana), além do Suriname e da Guiana na condição de mais novos membros da comunidade sul-americana após o processo de descolonização.

Passos, ainda observa que (1998, p. 115):

O primeiro passo oficial surgiu em 1976, (...) com a busca da diplomacia brasileira de uma maior cooperação com os países latino-americanos. Foi feita uma primeira sondagem com este intuito em março de 1977. A reação dos países foi positiva em sua maioria. A atitude mais reservada deu-se por parte da Venezuela, que hesitou consideravelmente e aderiu após perceber o isolamento em que se encontrava manifestando sua oposição;

Em verdade, não foi a motivação meramente comercial que levou ao alinhamento do Tratado de Cooperação Amazônica, havia uma tendência quase universal de sistemas mais eficientes ou precárias de acordos cooperativos na gestão de recursos naturais, mais especificamente de recursos hídricos. Nasceu assim, da "consciência ecológica", a ideia fundante do Tratado de Cooperação Amazônica, a despeito do reforço de soberania sobre a região (SILVEIRA, 2005, p. 59).

Com as ressalvas de se tratar de um discurso oficial, mas por ocasião da assinatura do Tratado supra, o discurso proferido pelo então Presidente Ernesto Geisel dá mostras da 
finalidade distinta dos pactos até então firmados na região, que se restringiam a estimular o comércio entre nações ou um mercado comum.

Aproximar, em todos os níveis, populações e Governos Amazônicos e dar caráter de continuidade a essa aproximação, eis resumido, o programa que o Tratado se propõe a realizar. Cumpridas essas metas, estarão preenchidas as condições para que, em desdobramento natural, se identifiquem projetos e áreas suscetíveis de cooperação (...).

Num mundo em que advertências responsáveis sensibilizaram para a perigosa redução dos recursos naturais, a Amazônia apresenta-se com opulência de elementos vitais ao desenvolvimento e à própria sobrevivência. Água, energia, terra, trindade básica a que se podem acrescentar a madeira e os minérios, representam os dados brutos que falam eloquentemente da viabilidade da Amazônia como projeto. E, articulando esses elementos uns aos outros e com o oceano, a mais completa das reses de caminho fluviais.

Aperfeiçoar as condições de navegabilidade, construir portos e armazéns, levar avante estudos hidrológicos e de clima, tais são, pois as primeiras tarefas a propor à colaboração amazônica.

(...)

Prioridade, ao menos igual, se deverá conceder ao intercâmbio de experiências em matéria de desenvolvimento regional e à conjugação de esforços na pesquisa científica e tecnológica. (...)

Essa tecnologia, nós é que a teremos de encontrar, pois de nada vale recorrer ao tradicional comodismo, que nos fez, no passado, importadores de tecnologia dispendiosas, nem sempre adequadas às nossas necessidades (MINISTÉRIO DAS RELAÇÕES EXTERIORES apud SILVEIRA, 2005, p. 62-63).

O principal objetivo consistia em implantar um mecanismo permanente de concertação entre os governos e os setores técnicos dos países amazônicos com vistas à cooperação nas áreas de caráter não econômico (CERVO, 2001, p. 230). 
Conforme o Artigo II, o Tratado se aplica nos territórios das Partes Contratantes na Bacia Amazônica, assim como, também, em qualquer território de uma Parte Contratante que, pelas suas características geográficas, ecológicas ou econômicas, se considere estritamente vinculado à mesma.

Dentre outros aspectos contemplados pelo TCA, destaca-se a colaboração entre os países membros para promoção de pesquisa científica e tecnológica e o intercâmbio de informações e colaborações; serviços de saúde e melhoria das condições sanitárias; estabelecimento de uma adequada infraestrutura de transportes e comunicações; incremento do emprego racional dos recursos humanos e naturais e promoção do desenvolvimento econômico e social dos territórios; incremento do turismo e o comércio transfronteiriço e conservação do patrimônio etnológico e arqueológico. No que tange aos recursos hídricos, a disciplina do TCA limitou-se a assegurar a liberdade de navegação nos rios amazônicos e a previsão (genérica) de utilização racional dos recursos naturais, em que pese a previsão de que o uso e aproveitamento dos recursos naturais nos respectivos territórios é direito inerente à soberania do Estado,

Quanto à estrutura organizacional, foi previsto pelo TCA a criação de um Conselho de Cooperação Amazônica, de uma Secretaria, de Comissões Nacionais Permanentes e de Comissões Especiais. As medidas previstas deveriam ser adotadas mediante ações bilaterais ou de grupos de países, com o objetivo de promover o desenvolvimento harmonioso de seus respectivos territórios, uma vez que o TCA permite celebrar acordos sobre temas específicos e tem a flexibilidade para ajustar-se às mudanças e necessidades de cada região.

\section{Cooperação Internacional entre os países amazônicos e com entidades não amazônicas}

Por meio do Tratado de Cooperação Amazônica, os oito países signatários buscam realizar esforços e ações conjuntas a fim de promover o desenvolvimento harmônico de seus respectivos territórios amazônicos, de modo a produzir resultados equitativos e mutuamente 
proveitosos, bem como para a preservação do meio ambiente e a conservação e a utilização racional dos recursos naturais desses territórios, consoante assevera o artigo $1^{\circ}$ do Acordo.

Como mencionado, os países amazônicos perceberam a necessidade de tratamento conjunto dos problemas que afligem a região amazônica, região rica em recursos naturais, mas que tem em sua complexidade o grande desafio dos governos para preservá-la.

Além de sua importância econômica, na medida em que seu manejo adequado é fundamental para o desenvolvimento local, a Amazônia tem grande valor estratégico, tendo em vista a quantidade de água potável disponível em seus rios, geradora da cobiça por parte de estados que se veem em um futuro não muito distante com sérias dificuldades hídricas.

Dessa forma, buscou-se apresentar medidas que se mostraram mais eficazes para a preservação e o uso sustentável das riquezas amazônicas, essa iniciativa conjunta dos países membros da OTCA é vista por eles como medidas necessárias para asseverar sua soberania sobre a região e abrandar os clamores pela internacionalização da Amazônia.

Domingues, ressalta que (2016, passim):

Após a $2^{\text {a }}$ Guerra Mundial, surgiram expressões do tipo soberania limitada, restrita, compartilhada, dever de ingerência, intervenção humanitária e outras. Embora criadas por personalidades notáveis, essas expressões vêm acarretando consequências danosas, principalmente para os países mais pobres ou em desenvolvimento.

Em razão desses novos conceitos, que conflitam com as normas de Direito Internacional, e com textos de diplomas do mais alto nível, como as cartas da ONU e da OEA e outras convenções internacionais, alguns tratados, já acordados no cenário mundial, não vêm sendo respeitados ou cumpridos, principalmente, pelas nações mais ricas.

É neste contexto que o processo de cooperação/integração dos países amazônicos deve ser o objetivo primordial a ser alcançado, buscando, na prática, executá-lo de forma eficaz e independente, através das várias iniciativas de ações e projetos com vistas ao desenvolvimento econômico-social da região e dos países que a detém. Visto que sua 
concretização é um instrumento garantidor do pleno poder dos países amazônicos sobre o seu espaço, torna-se imperioso "integrar para não entregar".

A tarefa, contudo, é árdua, devido a mencionada complexidade da região, que carece de conexão física adequada a permitir o livre trânsito por seu território, e à carência de recursos financeiros para lidar com essas dificuldades. Por isso a necessidade de fortalecer as ações da Organização do Tratado de Cooperação Amazônica, por intermédio de sua Secretaria Permanente, no sentido de fomentar ainda mais as iniciativas multilaterais dos países amazônicos, bem como de atrair a cooperação de agências internacionais.

Nesse sentido dispõe o sítio eletrônico da OTCA:

A importância da Cooperação Internacional para o funcionamento da Organização do Tratado de Cooperação Amazônica (OTCA) é reconhecida pelos Países Membros que decidiram em reunião do Conselho de Cooperação Amazônica (CCA), realizada no Rio de Janeiro, Brasil, no dia 14 de maio de 2010, aperfeiçoar e fortalecer institucionalmente esse processo. Para tanto, destacaram a necessidade de estabelecer procedimentos, mecanismos e termos para consideração, negociação e assinatura de propostas de acordo entre a Secretaria Permanente e terceiros países, organismos internacionais e/ou outras entidades.

Em seguida, destaca-se que a Organização tem assinados diversos memorandos de entendimento com várias entidades e agências internacionais como o Banco Interamericano de Desenvolvimento (BID), o Banco Mundial, a Organização dos Estados Americanos (OEA), o Programa das Nações Unidas para o Desenvolvimento (PNUD), o Programa das Nações Unidas para o Meio Ambiente (PNUMA), a União Europeia, entre outros organismos.

Damasceno, França e Silva Junior (2016, passim), destacam que: 
A proposta da integração sub-regional, de uma gestão integrada dos recursos naturais e da promoção do desenvolvimento sustentável, fundamentalmente requer o envolvimento de todos os países amazônicos, sem deixar de lado as ONGs e a cooperação internacional em geral, com os quais é necessário manter um diálogo permanente e fluido. É por isto que a OTCA, desde a sua criação, tem buscado alianças estratégicas, que ajudam a cumprir os objetivos e metas propostas pela Organização. Desta forma, espera-se maior ganho de visibilidade e reconhecimento institucional, convertendo a OTCA em uma organização de referência regional obrigatória para o desenvolvimento e financiamento das atividades organizacionais e de cooperação, assim como das ONGs.

\section{A consubstancialização da OTCA: projetos em andamento}

Com a assinatura do Tratado de Cooperação Amazônica os países membros de comprometeram a realizar esforços e ações conjuntas para promover o desenvolvimento harmônico de seus territórios, mediante a conservação e o uso racional dos recursos naturais com resultados equitativos e de proveito mútuo.

Esse compromisso foi fortalecido com a instituição da Organização do Tratado de Cooperação Amazônica, e a substituição da Secretaria "Pro Tempore", exercida em caráter rotativo, pela Secretaria Permanente. A partir de então, diversos acordos foram assinados e programas e projetos foram implementados com o objetivo de estimular o desenvolvimento sustentável da Amazônia.

Como aduz Domingues (2016, passim),

O Tratado de Cooperação Amazônica, como experiência regional de grande significado para o desenvolvimento da região, tem passado por inúmeras reestruturações, desde sua criação, em 1978. Tal mecanismo se encontra numa etapa de fortalecimento políticoinstitucional, de ativa cooperação para o desenvolvimento sustentável da Amazônia. 
Esses programas e projetos são colocados em prática pela Secretaria Permanente da Organização, cuja criação influiu positivamente na agilização dos procedimentos no marco do Tratado e na dinamização da execução das decisões. Em sua tarefa, a Secretaria atua em conformidade com o decidido pelos países membros e os planos estratégicos da Organização.

Destacam-se entre os principais projetos de cooperação os seguintes (ORGANIZAÇÃO, 2016, passim):

\subsection{Monitoramento do Desflorestamento, Aproveitamento Florestal e Mudanças de Uso do solo na Floresta}

Tem a finalidade de apoiar os membros no fortalecimento do diálogo e de manejo da floresta, por intermédio do monitoramento e do acompanhamento das mudanças no uso do solo. Trata-se de projeto que demonstra bem a posição da OTCA de obter recursos de outras fontes que não os signatários, pois é financiado pela Organização Internacional de Madeiras Tropicais (OIMT).

\subsection{Projeto Manejo Integrado e Sustentável dos Recursos Hídricos Transfronteiriços da Bacia do Rio Amazonas}

Também denominado de GEF Amazonas, visa desenvolver o Plano Estratégico de Ação para a Bacia Amazônica, ferramenta indispensável para o uso sustentável e a gestão conjunta dos recursos hídricos da Bacia, bem como a fomentar a adaptação às mudanças climáticas. $\mathrm{O}$ projeto se baseia em diversos eixos, que vão desde o entendimento da sociedade amazônica ao 
monitoramento e avaliação do próprio projeto. A exemplo do projeto anterior, dispõe de cooperação de organismo externo, já que é financiado pelo Global Environment Facility.

\subsection{Projeto Sistema de Vigilância em Saúde Ambiental na Região Amazônica}

Tem como perspectiva a construção de um sistema consensual de indicadores e estratégias para institucionalizar a vigilância sanitária em saúde ambiental na Amazônia.

\footnotetext{
A partir desta iniciativa, se espera que os responsáveis pelas políticas públicas possam determinar os fatores de risco e as ações direcionadas à vigilância em saúde ambiental em seus países. Isso facilitará a prevenção, proteção, adaptação e mitigação em casos provenientes das mudanças climáticas e outros que afetem a saúde humana, como danos ambientais e contaminação. O projeto é realizado pela Organização do Tratado de Cooperação Amazônica (OTCA) com o apoio financeiro do Banco Interamericano de Desenvolvimento (BID), a Cooperação Técnica da OPS-OMS, FIOCRUZ, UNAMAZ, IEC e outros (ORGANIZAÇÃO, 2016, passim).
}

Como se vê, trata-se de mais um projeto com auxílio financeiro que não dos países membros, como o Banco Interamericano de Desenvolvimento (BID) e a Organização Mundial da Saúde (OMS).

\subsection{Programa Uso Sustentável e Conservação de Florestas e da Biodiversidade na Região}

\section{Amazônica}

Também denominado de Programa Regional Amazônia (PRA), está em sua segunda fase de execução e responde à necessidade de fortalecer a cooperação para o manejo sustentável 
dos recursos naturais da região amazônica, contemplando as florestas, o biocomércio, o turismo sustentável, assuntos indígenas e o fortalecimento institucional.

O programa é fruto da cooperação entre a OTCA, a Cooperação Internacional dos Países Baixos (DGIS) e a Cooperação para o Desenvolvimento da Alemanha (BMZ e GIZ).

\subsection{Projetos Demonstrativos nos Países Membros}

Por intermédio do Programa Regional Amazônia (PRA), a OTCA promove a execução de programas demonstrativos locais no território dos países amazônicos, programas esses que servem de incentivo ao recrudescimento do manejo florestal comunitário e ao uso sustentável da biodiversidade.

Esses projetos oferecem a oportunidade de aplicar, na prática, os esforços de coordenação regional para abordar questões específicas ou de interesse comum no âmbito nacional, a fim de contribuir para o processo regional de desenvolvimento sustentável. Atualmente são desenvolvidos dois projetos demonstrativos, quais sejam o Projeto Binacional Acre - Ucayali e o Projeto Trinacional para Conservação e Desenvolvimento Sustentável do Corredor de Gestão entre as Áreas Protegidas La Paya (Colômbia), Güeppi (Peru) e Cuaybeno (Equador).

O primeiro tem por objetivo contribuir com a gestão conjunta dos recursos da flora e da fauna silvestres em zonas de alto interesse sociocultural e ambiental na área fronteiriça e realizase por intermédio do fortalecimento do Foro de Integração Fronteiriça na região de fronteira entre Peru (Ucayali) e Brasil (Acre). O projeto conta com a participação ativa de ONGs e de indígenas e com o apoio financeiro da Fundação Peruana para a Conservação da Natureza "ProNatureza" e da ONG "SOS Amazônia". 
O segundo projeto foi implementado para contribuir com a consolidação do Corredor de Gestão “La Paya-Güeppi-Cuyabeno”, como modelo de conservação e de desenvolvimento sustentável regional de áreas protegidas, mediante o gerenciamento conjunto e o manejo coordenado entre Colômbia, Peru e Equador.

\section{Conclusão}

Percebendo a necessidade de fortalecer sua soberania sobre a Amazônia, evitando os anseios por sua internacionalização, bem como a urgência de um modelo conjunto de manejo e uso sustentáveis da região, os países amazônicos firmaram o Tratado de Cooperação Amazônica em 1978, e posteriormente fundaram a Organização do Tratado de Cooperação Amazônica, de modo a melhor institucionalizar a iniciativa.

A OTCA tem por objetivo ser um espaço político de diálogo regional, para buscar consensos e convergências em temas de importância para o futuro da Amazônia. A ideia fundamental é que a região não seja mais vista de forma compartimentalizada, com oito pedaços pertencentes a oito países diferentes, mas como um espaço comum, que deve ser protegida e utilizada com base em projetos de gestão compartilhada, sem abrir mão, contudo, do poder supremo desses estados em face da cobiça de países de fora da região.

Atualmente, estão em execução 23 iniciativas, projetos e programas, em áreas como meio ambiente, assuntos indígenas, ciência e tecnologia, saúde, turismo e inclusão social. Entre eles, destaca-se o Projeto Monitoramento da Cobertura Florestal na Região Amazônica, cujo objetivo é contribuir para o desenvolvimento regional da capacidade de monitoramento da floresta amazônica, por meio de instalação de salas de observação nos países-membros e de capacitação e intercâmbio de experiências em sistemas de monitoramento. 
Do exposto se percebe que a renovação do compromisso dos países amazônicos com o TCA, realizada com o estabelecimento da OTCA, se afigura como uma importante e necessária medida face ao imperativo de desenvolver a Amazônia com bases sustentáveis e proteger o patrimônio ambiental que ela oferece aos países que sobre ela detém poder soberano, especialmente a suas populações, que serão as maiores beneficiadas do desenvolvimento econômico passível de ser atingido com o devido respeito às suas riquezas.

\section{Referências}

CERVO, Amado Luiz. Relações Internacionais da América Latina: velhos e novos paradigmas. Brasília: IBRI-UnB, 2001.

DAMASCENO, João Pedro Tavares; FRANÇA, Matheus Gonçalves; SILVA JUNIOR, Lauis de Oliveira. Integração Regional e Desenvolvimento Sustentável: o Desafio do Tratado de Cooperação Amazônica. Disponível em: <https://nupeat.iesa.ufg.br/up/52/o/11_Integra___o_regional_e_desenvolvimento.pdf >. Acesso em 19 jan 2016.

DOMINGUES, Leyza Ferreira Domingues. O tratado de cooperação amazônica e sua repercussão no processo de integração/cooperação dos países membros na expressão de sua soberania frente à ameaça internacional. Disponível em: <http://egov.ufsc.br/portal/sites/default/files/anexos/21972-21973-1-PB.pdf>. Acesso em 20 jan 2016.

MAGAlHÃES, Carlos Alberto Simas. O Tratado de Cooperação Amazônica: um instrumento de ação diplomática. 110f. Monografia - Vigésimo Sexto Curso de Altos Estudos do Instituo Rio Branco, Rio de Janeiro, 2014. Digitado.

MARCIANO, Sandra Maria. O Tratado de Cooperação Amazônica - um projeto de integração sul-americana: "entre o idealismo jurídico e o realismo geográfico". 185f. Dissertação (Mestrado) - pós-Graduação em Geografia Humana, Universidade de São Paulo, São Paulo, 2002. Digitado.

ORGANIZAÇÃO DO TRATADO DE COOPERAÇÃO AMAZÔNICA. Projetos e Programas. Disponível em: <http://otca.info/portal/projetos-programas.php?p=agd>. Acesso em 19 jan 2016.

PASSOS, Rodrigo Duarte Fernandes dos. Pragmatismo responsável e política de poder: a política externa do Governo Geisel. 1998. 137f. Dissertação (Mestrado) - Pós-Graduação em Ciência Política, Universidade de São Paulo, São Paulo, 1998. Digitado.

SILVEIRA, Edson Dama da. Direito socioambiental: Tratado de Cooperação Amazônica. Curitiba: Juruá, 2005. 